Article

\title{
Effect of Lactic Acid Fermentation on Color, Phenolic Compounds and Antioxidant Activity in African Nightshade
}

\author{
Alexandre Degrain ${ }^{1,2}$, Vimbainashe Manhivi ${ }^{1}$, Fabienne Remize ${ }^{2, *(D)}$, Cyrielle Garcia ${ }^{2}$ (D) and \\ Dharini Sivakumar ${ }^{1}(\mathbb{D}$ \\ 1 Phytochemical Food Network Research Group, Department of Crop Sciences, Tshwane University of \\ Technology, Pretoria West 0001, South Africa; alexandre974.degrain@gmail.com (A.D.); \\ vimbainashed@gmail.com (V.M.); SivakumarD@tut.ac.za (D.S.) \\ 2 QualiSud, Université de La Réunion, CIRAD, Université Montpellier, Montpellier SupAgro, \\ Université d'Avignon, 97490 Sainte Clotilde, France; cyrielle.garcia@univ-reunion.fr \\ * Correspondence: fabienne.remize@univ-reunion.fr; Tel.: +27-012-382-5303
}

Received: 3 August 2020; Accepted: 23 August 2020; Published: 30 August 2020

\begin{abstract}
This study aimed to investigate the influences of fermentation at $37{ }^{\circ} \mathrm{C}$ for 3 days by different lactic acid bacterium strains, Lactobacillus plantarum (17a), Weissella cibaria (21), Leuconostoc pseudomesenteroides (56), W. cibaria (64) or L. plantarum (75), on color, $\mathrm{pH}$, total soluble solids (TSS), phenolic compounds and antioxidant activity of African nightshade (leaves). Results indicated fermentation with L. plantarum 75 strain significantly decreased the $\mathrm{pH}$ and total soluble solids, and increased the concentration of ascorbic acid after 3 days. L. plantarum 75 strain limited the color modification in fermented nightshade leaves and increased the total polyphenol content and the antioxidant activity compared to the raw nightshade leaves. Overall, L. plantarum 75 enhanced the functional potential of nightshade leaves and improved the bioavailability of gallic, vanillic acid, coumaric, ferulic ellagic acids, flavonoids (catechin, quercetin and luteolin) and ascorbic acid compared to the other lactic acid bacterium strains. Correlation analysis indicated that vanillic acid and $p$-coumaric acid were responsible for the increased antioxidant activity. Proximate analysis of the fermented nightshade leaves showed reduced carbohydrate content and low calculated energy.
\end{abstract}

Keywords: traditional leafy vegetables; polyphenols; postharvest processing; FRAP activity; proximate analysis

\section{Introduction}

The indigenous leafy vegetable African nightshade (Solanum retroflexum Dun.) is a popular food in Venda, Limpopo Province, South Africa. Nightshade leaves are a rich source of the minerals Ca (199 mg/100 g), Mg (92 mg/100 g) and Fe (7.2 mg/100 g), and the raw leaves are rich in rutin [1]. Generally, the consumption of nightshade leaves is in fresh form after cooking, but they have a limited shelf life due to their highly perishable nature. Traditional methods of preserving these indigenous vegetables includes fermentation [2]. Lactic acid bacteria (LAB) are a group of gram-positive bacteria that convert sugars in food into lactic acid. Lactic acid fermentation is one of the oldest forms of food preservation and is affordable at the rural level. Lactic acid fermentation improves the aroma compounds, sensory properties, nutritive compounds (mainly folate, riboflavin, cobalamin, and ascorbic acid), low-calorie polyols (mannitol and sorbitol) and reduces anti-nutritive compounds [3].

Lactic acid fermentation increased the total phenols, flavonoids and antioxidant activity in the indigenous vegetable Momordica charantia (bitter melon) [4]. The lactic acid-fermented indigenous fruit camu-camu (Myrciaria dubia) and soymilk demonstrated antioxidant and anti-diabetic activities by 
inhibiting $\alpha$-amylase and $\alpha$-glucosidase activity [5]. Fermentation of African nightshade (S. Scabrum) using L. plantarum BFE 5092 and Lactobacillus fermentum BFE 6620 starter strains showed a significant impact on the bacterial composition by reducing the spoilage and pathogenic microorganism populations due to a reduction in $\mathrm{pH}$ and production of lactic acid [6].

L. plantarum has the "generally regarded as safe" (GRAS) status, warranting the safety of the bacterium for consumption [7]. The LAB strains can have probiotic properties, and the lactic-fermented foods provide beneficial effects on human gastrointestinal health [6].

However, limited information is available on the changes in different phenolic components or antioxidant properties of traditional underutilized vegetables after fermenting with different LAB strains. Furthermore, the use of LAB (e.g., some L. plantarum strains) as starter cultures in vegetable fermentation increases the control of fermentation. Weissella cibaria, Weissella confusa and Leuconostoc pseudomesenteroides are used in the food sector because these LAB strains produce exopolysaccharides [7]. W. cibaria isolated from fermented vegetables produces bacteriocin and weisseillicin, the natural peptides that can control food-borne pathogens or spoilage microorganisms [8]. Furthermore, the acidification of foods by organic acids produced by LAB stains and bacteriocins during fermentation can extend the shelf life and improve the safety of the product for consumption [9].

In this study, we investigated the influence of five different LAB strains, which had previously been isolated from plant materials and selected for their fermentative and stress resistance characteristics [3], on nightshade leaves during fermentation to select the suitable strains that showed a positive influence on physicochemical properties, phenolic profile and antioxidant property for development of a future functional food. The proximate analysis of the fermented nightshade leaves was included in the study, after selecting the suitable LAB strain.

\section{Materials and Methods}

\subsection{Chemicals}

Acetonitrile, 2,5-dihydroxybenzoic, vanillic, gallic, $p$-coumaric, ferulic, caffeic and ellagic acids, pyrogallol, epicatechin, catechin, quercetin, luteolin ( $\geq 95.0-98 \%)$, Man Rogosa Sharpe agar and other chemicals were purchased from Merck, Germiston, South Africa.

\subsection{Plant Material}

The irrigation scheme in Thulamela Municipality, Venda, Limpopo Province, harvested the nightshade leaves during the winter season in 2019, as described by Managa et al. (2020) [1]. The leaves were detached from the stem, rinsed in tap water, disinfected ( $5 \mathrm{~min}$ ) with $\mathrm{NaOCl} 5 \%$, rinsed further with distilled water to remove the excess chlorine from the leaves, blanched in a water bath at $95^{\circ} \mathrm{C}$ for $5 \mathrm{~min}$ and subsequently placed in screw cap bottles ( $75 \mathrm{~g}$ of leaves per bottle) to cool to $30^{\circ} \mathrm{C}$ before adding $0.8 \% \mathrm{NaCl}$ sterile solution.

\subsection{Starter Cultures and Fermentation of Nightshade Leaves}

LAB strains used in the study came from culture collections from University of La Réunion, QualiSud [3]. L. plantarum $17 a$ and 75 were isolated from papaya and cabbage respectively. W. cibaria 21 and 64 originated from cabbage, as did L. pseudomesenteroides 56.

LAB strains were grown on Man Rogosa Sharpe (MRS) agar at $30{ }^{\circ} \mathrm{C}$ for $72 \mathrm{~h}$. The strain reactivation involved one or two colonies being suspended in $9 \mathrm{~mL}$ of MRS broth, incubated at $30^{\circ} \mathrm{C}$ for $48 \mathrm{~h}$ and centrifuged at $8000 \times g$ for $5 \mathrm{~min}$. The cell pellets were washed and rinsed twice with sterile distilled water, and then re-suspended in $20 \mathrm{~mL}$ of sterile water to obtain a concentrated cell culture. Thereafter, nightshade leaves, inoculated with LAB (approximately $1 \times 10^{8} \mathrm{CFU} / \mathrm{mL}$ ), were placed at $30^{\circ} \mathrm{C}$, without agitation, for 3 days (duration of fermentation); holding the fermented products at $-20^{\circ} \mathrm{C}$ for $15 \mathrm{~min}$ stopped fermentation. Fermentation was performed in triplicate for each LAB strain. 


\subsection{Physicochemical Properties and Ascorbic Acid Content}

All measurements took place on day 3 after fermentation. Total color difference $(\Delta \mathrm{E})$ was determined using a colorimeter (CR-400 Chroma Meter), according to Managa et al. (2020) [1]. The $L^{*}$ (lightness), $a^{*}$ (greenness) $b^{*}$ (yellowness) color components determined the $\Delta E$ of each composite sample using the following formula: (1) Fresh leaf samples' color coordinate values are $L_{1}{ }^{*}$, $a_{1}{ }^{*}, b_{1}{ }^{*}$ and the samples from fermentation treatments with LAB strains represent $L_{2}{ }^{*}, a_{2}{ }^{*}$, and $b_{2}{ }^{*}$

$$
\Delta \mathrm{E}_{a b}^{*}=\sqrt{\left(L_{2}^{*}-L_{1}^{*}\right)^{2}+\left(a_{2}^{*}-a_{1}^{*}\right)^{2}+\left(b_{2}^{*}-b_{1}^{*}\right)^{2}}
$$

The $\mathrm{pH}$ of the brine, before and after mixing with leaves $(10 \mathrm{~mL})$, was sterilely taken from the bottles, and the $\mathrm{pH}$ values recorded using a digital $\mathrm{pH}$ meter (Mettler-Toledo Instruments Co., Shanghai, China) at $24 \mathrm{~h}$ intervals up to 3 days.

A refractometer measured the total soluble solids (TSS) of the brine solution, after mixing the leaves (Agato pocket PAL-2, Tokyo, Japan) up to day 3, and expressed as \%TSS. After testing each sample, the refractometer was calibrated using distilled water.

Ascorbic acid content was determined via titration using 2,6 dichlorophenol indophenol dye, according to AOAC [10].

\subsection{Quantification of Targeted Phenolic Compounds Using HPLC-DAD and Total Polyphenolic Content}

Concentrations of phenolic acids and flavonoids were quantified from snap frozen samples using HPLC analysis, performed using the Shimadzu liquid chromatograph system (Shimadzu Corp, Kyoto, Japan) equipped with a quaternary pump, a vacuum degasser, C18 column and an auto sampler and DAD detector, described by Mpai et al. (2018) [11], without any modifications. The homogenized sample $(1 \mathrm{~g})$ was extracted in a solution mixture containing $10 \mathrm{~mL}$ of methanol and 1\% butylated hydroxytoluene using an ultrasonic bath for $45 \mathrm{~min}$. The HPLC had an aliquot of $10 \mu \mathrm{L}$ injected into it, and each sample was analyzed in triplicate [11]. The gradient system included solvent A (methanol: acetic acid: deionized water, 10:2:88) and solvent B (methanol: acetic acid: deionized water, 90:2:8). Different gradient programs were tested and the most effective gradient program started with $100 \% \mathrm{~A}$ at $0 \mathrm{~min}, 85 \% \mathrm{~A}$ at $5 \mathrm{~min}, 50 \% \mathrm{~A}$ at $20 \mathrm{~min}, 30 \% \mathrm{~A}$ at $25 \mathrm{~min}$, and 100\% B from 30 to $40 \mathrm{~min}$ as stated by Zeb [12]. The chromatograms were obtained using 280, 320 and $360 \mathrm{~nm}$ for analysis of phenolic compounds and the spectra were measured from 190 to $450 \mathrm{~nm}$. The identification was carried out by the peak identification, and quantification of phenolics was carried out using the standard and established calibration curves in the concentration range of 0.333 to $1.666 \mathrm{ng} / \mu \mathrm{L}$ curves [12]. The linear regressions with a correlation coefficient were established between 0.9991 and 0.9996 . Results for predominant phenolic acids and flavonoids were expressed in $\mathrm{mg} / \mathrm{kg}$ leaves.

\subsection{Ferric Reducing Antioxidant Power (FRAP) Assay}

The FRAP assay ( $\mu$ mol TEAC/100 g) was performed to determine the ferric reducing antioxidant power using FRAP reagent solution (10 mmol/L TPTZ (2,4,6-tris(2-pyridyl)-1,3,5-triazine)) acidified with concentrated $\mathrm{HCl}, 20 \mathrm{mmol} / \mathrm{L} \mathrm{FeCl}_{3}$, and nightshade leaves $(0.2 \mathrm{~g})$ homogenized in $2 \mathrm{~mL} \mathrm{CH}_{3} \mathrm{COONa}$ buffer at a pH of 3.6, as described by Managa et al. (2020) [1].

\subsection{Proximate Analysis of the Final Product}

Proximate analysis used standard methods, as reported by Managa et al. (2020) [1] without any modifications. Leaf samples (100 g) in three replicate samples were used for proximate analysis without modifications. Nitrogen content was determined using the Kjeldahl method; quantifying the nitrogen content was by converting it to protein and multiplying by a factor of 6.25. The hexane and soxhlet extraction method determined the fat content using $5 \mathrm{~g}$ of leaf samples. Dried ground leaf sample (2 g) was digested with $0.25 \mathrm{M} \mathrm{H}_{2} \mathrm{SO}_{4}$ and $0.3 \mathrm{M} \mathrm{NaOH}$ solution to 
determine the fibre content, and a dried powdered sample $(5 \mathrm{~g})$ was used to calculate the ash content. The estimation of the carbohydrate content used the following formula: 100 - (weight in grams (moisture + proteins + lipids + ash + fibres) in $100 \mathrm{~g}$ of leaves). Calorific value was calculated as $(\%$ proteins $\times 2.44)+(\%$ carbohydrates $\times 3.57)+(\%$ lipids $\times 8.37)$. A set of $20 \mathrm{mg}$ sample mixed with $12 \mathrm{~mL}$ of $\mathrm{HNO}_{3}$ and flame photometer quantified the Na content [10].

\subsection{Statistical Analysis}

The experiments, performed in a completely randomized design, had three to five replicates per treatment and the determinations repeated twice. One-way analysis of variance (ANOVA) analyzed the significant differences between different LAB strains on different parameters at $p<0.05$. Fisher's protected t-test, with a least significant difference (LSD) at 5\% level of significance, separated the treatment means. The statistical program Minitab for Windows (2018) analyzed the data.

\section{Results and Discussion}

\subsection{Effect of Fermentation on Physicochemical Parameters and Ascorbic Acid Content}

The initial $\mathrm{pH}$ value of the vegetable preparation was 6.34. The $\mathrm{pH}$ decreased rapidly after $24 \mathrm{~h}$ fermentation, irrespective of the LAB strain (Figure 1). The kinetics of the decrease differed between the two strains because the medium fermented with strain 75 reached a pH value of 5.60 after $24 \mathrm{~h}$ compared to 6.00 for strain $17 a$. The LAB strain 56 showed the smallest decrease in pH (5.83) after $24 \mathrm{~h}$ of fermentation.

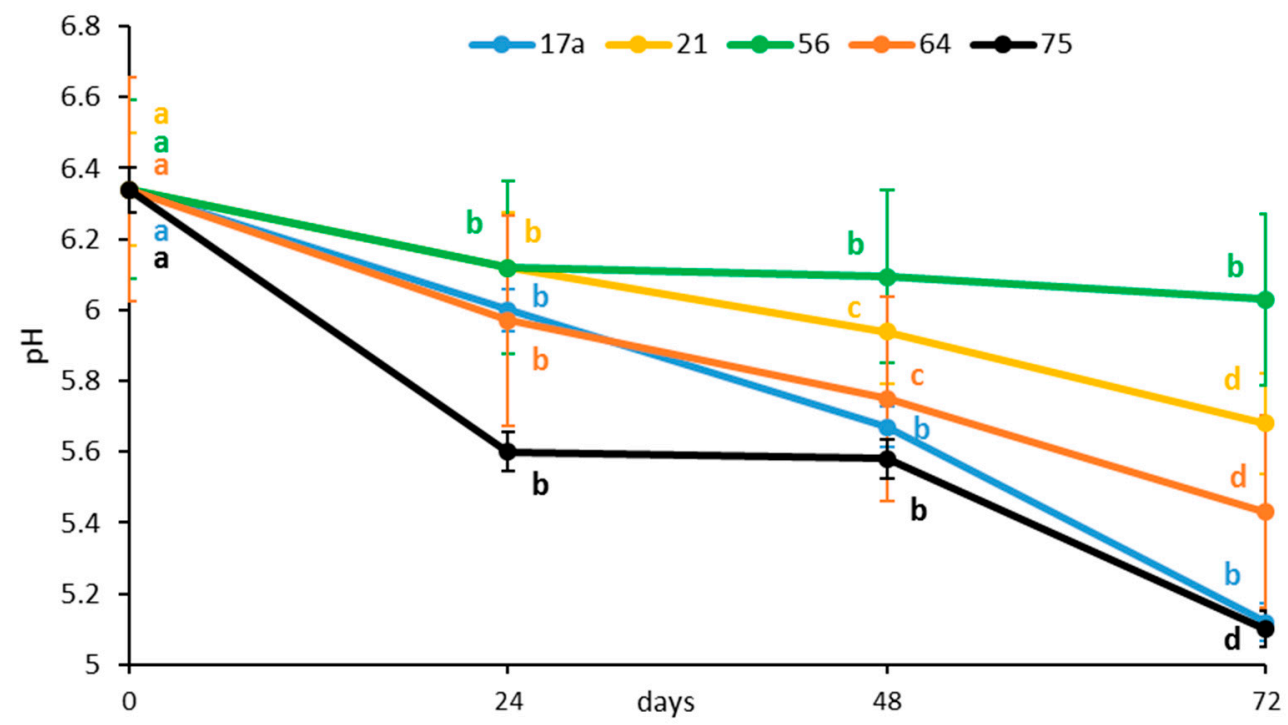

Figure 1. Influence of lactic acid fermentation with different LAB strains on $\mathrm{pH}$ of the brine solution of African nightshade (Solanum retroflexum) leaves. Each value represents the mean value of three replicate samples. Means followed by the same letter within a series are not significantly different $(p<0.05)$.

The results further showed that during the entire fermentation process at each incubation time point, the inoculation of strain LAB $17 a$ consistently lowered the $\mathrm{pH}$. The starter cultures, LAB strains 75 and $17 a$, reduced the $\mathrm{pH}$ (5.20) significantly after $72 \mathrm{~h}$ of fermentation. Production of various organic acids, with lactic acid as the predominant acid, could have contributed to the low $\mathrm{pH}$ [13]. The LAB strains produced lactic acid and $\mathrm{CO}_{2}$ from carbohydrates via carbohydrate metabolism pathways (Embden-Meyerhof, phosphoketolase, tagatose-6-phosphate, and Leloir pathways) and the carbonic acid produced during the metabolic pathway decreases the $\mathrm{pH}$ [13]. As a homofermentative bacterium, L. plantarum produces more lactic acid than heterofermentative W. cibaria [14]. Due to its lower $\mathrm{pKa}$ value (3.86), lactic acid acts as a stronger acidifier than the other organic acids, especially acetic acid 
(pKa value 4.76) [15]. The LAB fermentation helps to preserve food by making it hard for other microorganisms to thrive by decreasing the $\mathrm{pH}$. Reportedly, L. plantarum has similar $\mathrm{pH}$ changes due to higher lactic acid content during fermentation of Chinese sauerkraut [16].

The TSS content was significantly reduced after $24 \mathrm{~h}$ of fermentation regardless of the LAB strain used (Figure 2), indicating a fast utilization of sugars. Fermentation by strains $17 a$ and 64 showed the highest TSS $(6.87 \%)$ on day 3 ; the lowest TSS $(6.42 \%)$ was observed after fermenting for $72 \mathrm{~h}$ with strain 75. Sugars are the major soluble solids [17]. Kaprasob et al. (2017) [18] reported that the decrease in total sugar in fermented cashew apple juice was greater with L. plantarum, and the bacteria consumed sugar during the fermentation of this juice at a much faster rate. Reduction of TSS can be associated with bioconversion of sugar into lactic acid and consumption of sugar for the growth and metabolism of the bacteria. Similar decreases in TSS were reported during fermentation of traditional 'snake fruit' [19].

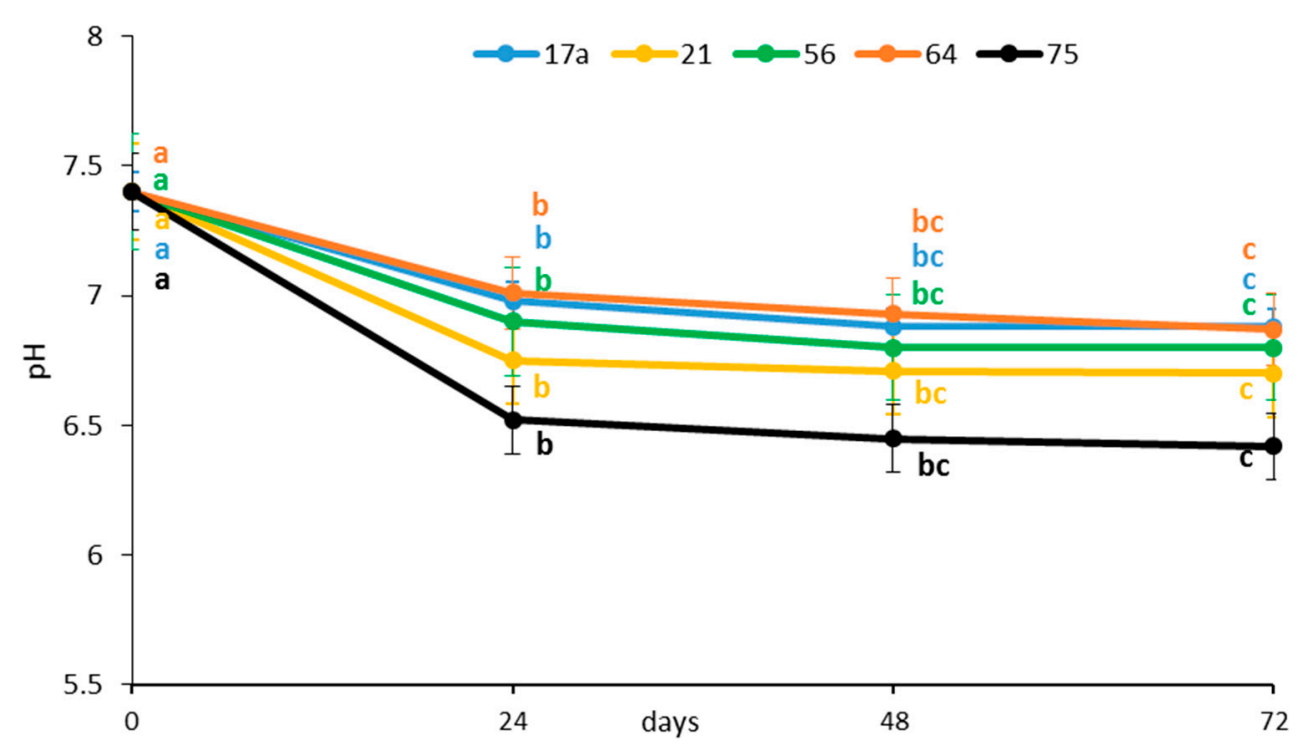

Figure 2. Influence of lactic acid fermentation with different LAB strains on total soluble solids of the brine solution of African nightshade (Solanum retroflexum) leaves. Each value represents the mean value of three replicate samples. Means followed by the same letter within a series are not significantly different $(p<0.05)$.

Fermentation with different $\mathrm{LAB}$ strains influenced the total color difference $\Delta \mathrm{E}$ in nightshade leaves (Figure 3). LAB strains $17 a$ and 75 caused the least total color difference compared to the raw leaves. After fermentation (day 3), LAB strains $17 a$ and 75 resulted in $\mathrm{pH}$ values of 5.2, whilst the other LAB species had higher values. Acetic acid produced by the heterofermentative bacteria degraded chlorophyll $a$ and $b$ more than lactic acid [20]. The $\Delta \mathrm{E}$ was significantly higher in leaves fermented with LAB strains 56 and 64 (Figure 3); this was probably due to the changes in $\mathrm{pH}$ during fermentation, which could have produced new compounds ( $\mathrm{Mg}$ free chlorophyll derivatives) and carotenoid with 5,8-epoxide groups or chemical oxidation of phenolic compounds, and the production of brown pigments (o-quinones) may have masked the original green color of the leaves [21]. The blanching treatment of the leaves at $95{ }^{\circ} \mathrm{C}$ for $5 \mathrm{~min}$ probably inactivated the polyphenol oxidase enzymes. 


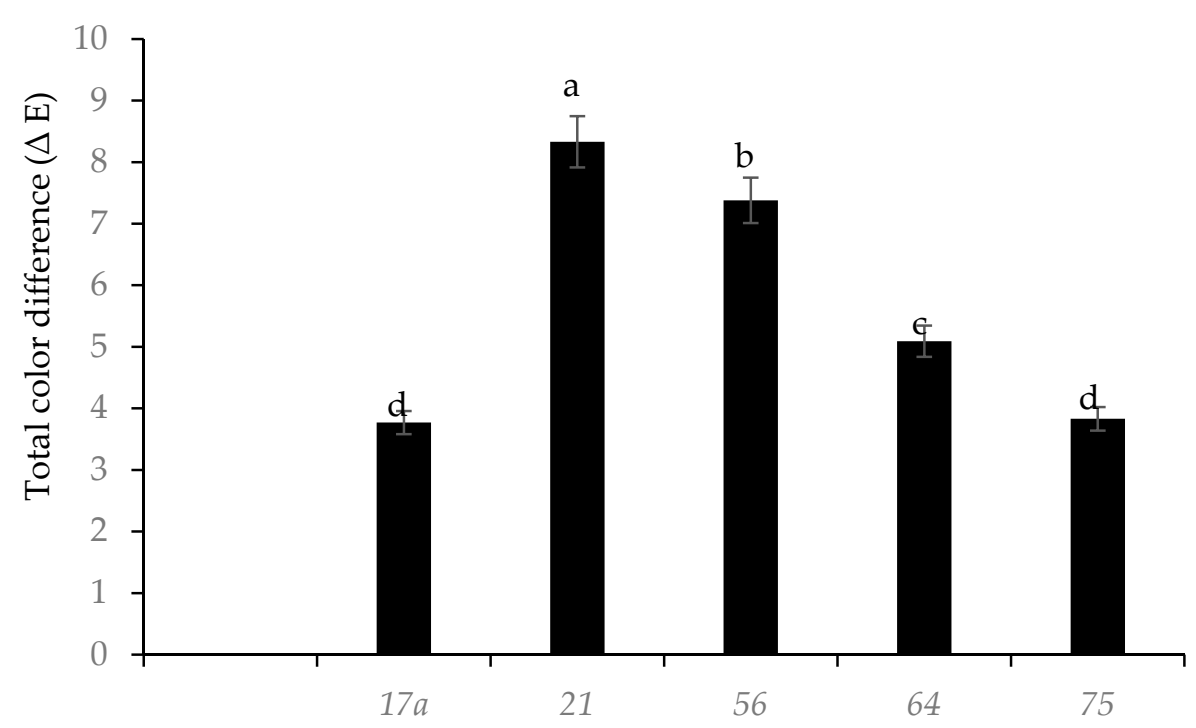

Figure 3. Influence of lactic acid fermentation with different LAB strains on color difference compared to raw (Solanum retroflexum) leaves. Each value represents the mean value of five replicate samples. Means followed by the same letter are not significantly different $(p<0.05)$.

Fermented leaves with LAB strains 75 and $17 a$ demonstrated the highest retention of ascorbic acid content (Figure 4). Cactus cladodes (Opuntia ficus-indica L.) [22] and amaranthus paste [23], showed a similar increasing trend in ascorbic acid after fermentation. In contrast, no increase in ascorbic acid was detected in pineapple juice fermented with LAB strains [24].

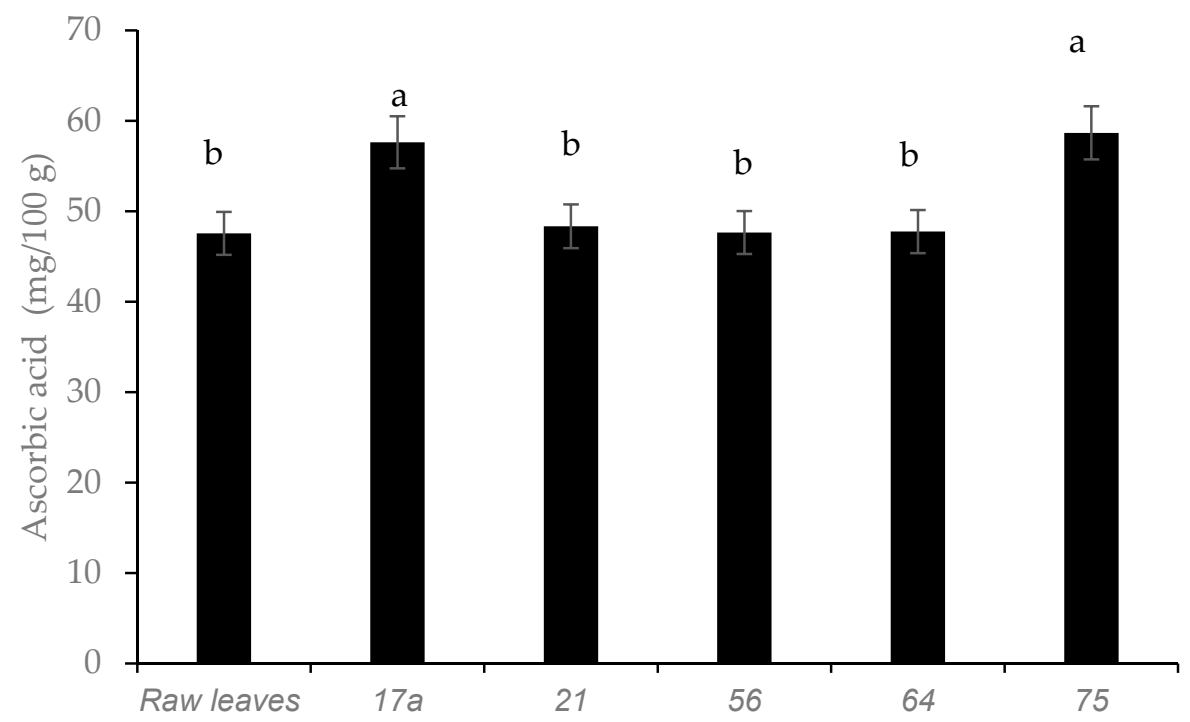

Figure 4. Influence of lactic acid fermentation with different LAB strains on ascorbic acid content in African nightshade (Solanum retroflexum) leaves. Each value represents the mean value of five replicate samples. Means followed by the same letter are not significantly different $(p<0.05)$.

\subsection{Phenolic Components and Antioxidant Activity}

Table 1 illustrates the influence of fermentation by different LAB strains on the changes of different phenolic compounds in nightshade leaves. In total, there were seven phenolic acids and three flavonoids quantified. 2,5-dihydroxybenzoic, coumaric acids and catechin were the predominant phenolic acids and flavonoids, respectively, in the lactic acid fermented nightshade leaves. LAB strain 75 demonstrated a significant increase in gallic $(281.0 \mathrm{mg} / \mathrm{kg})$, vanillic $(1352.0 \mathrm{mg} / \mathrm{kg})$, coumaric $(1577.0 \mathrm{mg} / \mathrm{kg})$, ellagic $(453.5 \mathrm{mg} / \mathrm{kg})$ acids, catechin $(1322.0 \mathrm{mg} / \mathrm{kg})$ and quercetin $(582.5 \mathrm{mg} / \mathrm{kg})$ after fermentation, 
whilst caffeic and ferulic acids were not detected. Ferulic and caffeic acids could possibly have been decarboxylated (phenolic acid decarboxylase) to other compounds, such as 4-vinylphenol, 4-vinyl guaiacol or 4-vinyl catechol, or could have been reduced by the action of phenolic acid reductase to hydroxyphenylpropionic acids, such as dihydrocaffeic and dihydroferulic acids [25]. Similarly, L. plantarum GK3 decarboxylated most of the phenolic acids apart from gallic acid. Strain GK11 decarboxylated most of the phenolic acids except ferulic acid [26]. Additionally, L. plantarum CECT $748^{\mathrm{T}}$ metabolized caeffeic, ferulic, $p$-coumaric and $m$-coumaric out of 19 food phenolic acids [27]. Decarboxylation of ferulic and caffeic acids could have affected the total polyphenol content in nightshade fermented with LAB strain 75 . The presence of vinyl derivatives at lower concentrations can provide a pleasant aroma but at higher levels, an undesirable flavor [28]. Fermentation with LAB strains 64 and 17a, showed the highest concentrations of caffeic and ferulic acids, respectively, probably due to the inability to use or metabolise these into vinyl derivatives [25]. LAB strain 56 significantly reduced the concentration of vanillic and ferulic acids after fermentation, possibly due to bacterial decarboxylation metabolism.

The significant reduction in gallic acid content after fermenting with strain 56 was due to decarboxylation by gallic acid decarboxylase to pyragallol; accumulation of pyragallol was detected (Supplementary Figure S1). The HPLC-DAD chromatogram showed lower levels of pyragallol after fermentation with strain 56 compared to 75 . Researchers have reported the activity of tannase and gallate decarboxylase in L. plantarum [29]. Thus, the increase in gallic and ellagic acid levels after fermentation is probably due to the tannase activity of LAB strain 75, resulting in bioconversion of gallotanins and ellargitannins. There was no detection of ellagic acid after fermentation with strains $17 a$ or 64 , or in raw leaves (Table 1 ).

Fermentation increased the catechin content in mottled cowpea [30]. Fermentation with LAB strains increased the flavonoid concentrations by converting the complex polyphenols to simple flavonoids [31]. The concentration of total polyphenolic compounds (TPC) in the fermented nightshade product increased from $6007.8 \mathrm{mg} / \mathrm{kg}$ (raw leaves) to $8638.0 \mathrm{mg} / \mathrm{kg}, 8246.5 \mathrm{mg} / \mathrm{kg}, 8016.8 \mathrm{mg} / \mathrm{kg}$, $5681.5 \mathrm{mg} / \mathrm{kg}$, and $3822.5 \mathrm{mg} / \mathrm{kg}$ after fermenting with LAB strains $75,17 a, 64,21$, and 56 respectively. Similarly, fermentation with LAB strains increased the total phenolic compounds in kiwi fruit [32]. LAB strains including L. plantarum possess $\beta$-glucosidase enzymes that can hydrolyze the flavonoid conjugates during fermentation and influence the bioavailability of polyphenols [32]. In addition, the stability of the phenolic compounds was associated with $\mathrm{pH}$, and a lower $\mathrm{pH}$ was reported to stabilize the $\mathrm{pH}$ [33]. After analyzing the above-mentioned changes related to phenolic compounds, the proposal is that overall, strain 75 enhanced accumulation of the majority of phenolic compounds other than caffeic and ferulic acids. The metabolization and transformation of the phenolic compounds differed between strain 75 and the others, probably due to the individual adaptability and ability of the strains to produce more hydrolytic enzymes [33].

This observed reduction in total phenolic compounds in nightshade leaves fermented with LAB strain 56 was probably due to detoxification and utilization of phenolic acids as a carbon source [22]. TPC showed a strong negative correlation $\left(r^{2}=-0.966, p<0.05\right)$ with the total color difference $(\Delta \mathrm{E})$, which confirms the chemical oxidation of phenolic compounds and production of browning pigments (o-quinones) [21]. This could have been the reason for the observed reduced color difference $(\Delta \mathrm{E})$ in leaves fermented with LAB strains 75 and $17 a$. 
Table 1. Influence of fermentation by different Lactobacillus strains on phenolic components of African nightshade (Solanum retroflexum) leaves.

\begin{tabular}{|c|c|c|c|c|c|c|c|c|}
\hline \multirow[b]{2}{*}{ Phenolic acids (mg/kg) } & & \multirow[b]{2}{*}{$\mathrm{RT}(\min )$} & \multirow[b]{2}{*}{ Raw leaves } & \multicolumn{5}{|c|}{ LAB Strain } \\
\hline & & & & $17 a$ & 56 & 64 & 21 & 75 \\
\hline Gallic acid & $\mathrm{C}_{7} \mathrm{H}_{6} \mathrm{OH}_{5}$ & 6.78 & $162.8 \pm 1.1^{d}$ & $178.0 \pm 1.3^{c}$ & $150.5 \pm 1.09$ e & $171.5 \pm 1.4^{\mathrm{cd}}$ & $210.0 \pm 1.7^{b}$ & $281.0 \pm 1.2^{\mathrm{a}}$ \\
\hline Caffeic acid & $\mathrm{C}_{9} \mathrm{H}_{8} \mathrm{O}_{4}$ & 20.55 & $360.5 \pm 1.4^{b}$ & $294 \pm 0.98^{c}$ & $77.5 \pm 0.21^{d}$ & $2145 \pm 1.4^{\mathrm{a}}$ & $395 \pm 1.9^{b}$ & nd \\
\hline Vanillic acid & $\mathrm{C}_{8} \mathrm{H}_{8} \mathrm{O}_{4}$ & 18.70 & $403.0 \pm 0.5^{b}$ & $343 \pm 2.3^{c}$ & $21.0 \pm 1.7^{\mathrm{e}}$ & $383.5 \pm 0.67^{b}$ & $245 \pm 0.98^{d}$ & $1352.0 \pm 1.23^{\mathrm{a}}$ \\
\hline 2,5 Dihydroxybenzoic acid & $\mathrm{C}_{7} \mathrm{H}_{6} \mathrm{O}_{4}$ & 14.50 & $1593 \pm 1.5^{c}$ & $2406 \pm 0.7^{b}$ & $489 \pm 1.8^{f}$ & $1003.3 \pm 2.2^{\mathrm{e}}$ & $1267 \pm 1.2^{\mathrm{d}}$ & $2827.5 \pm 1.4^{\mathrm{a}}$ \\
\hline p-Coumaric acid & $\mathrm{C}_{9} \mathrm{H}_{8} \mathrm{O}_{3}$ & 49.37 & $1115 \pm 0.76^{\mathrm{d}}$ & $1269.5 \pm 1.8^{c}$ & $929 \pm 1.8^{\mathrm{e}}$ & $1387.0 \pm 1.5^{b}$ & $980.5 \pm 2.1^{\mathrm{e}}$ & $1577 \pm 0.56^{\mathrm{a}}$ \\
\hline Ferulic acid & $\mathrm{C}_{10} \mathrm{H}_{10} \mathrm{O}_{4}$ & 20.61 & $1321 \pm 9.8^{\mathrm{d}}$ & $2343.0 \pm 1.2^{\mathrm{a}}$ & $1030 \pm 1.6^{\mathrm{e}}$ & $2000 \pm 1.9^{b}$ & $1487 \pm 1.6^{c}$ & nd \\
\hline Ellagic acid & $\mathrm{C}_{14} \mathrm{H}_{6} \mathrm{O}_{8}$ & 12.3 & nd & nd & $113.0 \pm 1.4^{\mathrm{c}}$ & nd & $191.0 \pm 1.6^{b}$ & $453.5 \pm 1.8^{a}$ \\
\hline Total phenolic acids & & & $4955.3 \pm 1.23^{d}$ & $6833.5 \pm 1.41^{\mathrm{b}}$ & $2810 \pm 1.12^{\mathrm{e}}$ & $7090.3 \pm 1.70^{a}$ & $4775.5 \pm 1.63^{d}$ & $6491 \pm 1.16^{c}$ \\
\hline \multicolumn{9}{|l|}{ Flavonoids (mg/kg) } \\
\hline Catechin & $\mathrm{C}_{15} \mathrm{H}_{14} \mathrm{O}_{6}$ & 12.75 & $726.5 \pm 2.5^{b}$ & $658.5 \pm 1.3^{\mathrm{cd}}$ & $574.5 \pm 0.78^{\mathrm{d}}$ & $669 \pm 1.3^{b c}$ & $602.0 \pm 0.45^{c}$ & $1322.0 \pm 1.7^{\mathrm{a}}$ \\
\hline Quercetin & $\mathrm{C}_{15} \mathrm{H}_{10} \mathrm{O}_{7}$ & 62.34 & $326.0 \pm 1.4^{\mathrm{d}}$ & $498.5 \pm 1.8^{b}$ & $438.0 \pm 1.7^{c}$ & $116.0 \pm 1.4^{\mathrm{f}}$ & $304.0 \pm 1.1^{\mathrm{e}}$ & $582.5 \pm 1.7^{\mathrm{a}}$ \\
\hline Luteolin & $\mathrm{C}_{15} \mathrm{H}_{10} \mathrm{O}_{6}$ & 20.00 & nd & $256 \pm 1.5^{a}$ & nd & $141.5 \pm 2.1^{c}$ & nd & $242.5 \pm 2.4^{b}$ \\
\hline Total flavonoids & & & $1052.5 \pm 1.21^{\mathrm{c}}$ & $1413.0 \pm 1.83^{b}$ & $1012.5 \pm 1.62^{c}$ & $926.5 \pm 0.95^{\mathrm{d}}$ & $906.0 \pm 1.86^{\mathrm{d}}$ & $2147.0 \pm 1.40^{\mathrm{a}}$ \\
\hline Total polyphenol content & & & $6007.8 \pm 1.34^{\mathrm{c}}$ & $8246.5 \pm 1.50^{b}$ & $3822.5 \pm 1.75^{\mathrm{d}}$ & $8016.8^{b}$ & $5681.5^{c}$ & $8638 \pm 1.69^{a}$ \\
\hline
\end{tabular}

Each value represents the mean value of five replicate samples. Means followed by the same letter within the row for a specific parameter are not significantly different $(p<0.05)$;

nd-not detected. 
Figure 5 presents the FRAP antioxidant activity of nightshade vegetables after fermentation. Fermentation by LAB strains 75 and $17 a$ increased the antioxidant activity of the nightshade leaves by $11.9 \%$ and $7.1 \%$, respectively, compared to the unfermented (raw) leaves. Nightshade leaves fermented with strain 56 showed the lowest antioxidant activity. Coumaric acid contributed significantly to the antioxidant property followed by vanillic and gallic acids (Supplementary Table S1). Therefore, an increase in antioxidant activities was associated with the release of phenolic compounds during fermentation. However, Kaprasob et al. (2017) [18] showed a decrease in antioxidant activity in cashew apple juice and explained that this could be due to oxidation of phenolic compounds. Numerous studies have underlined a beneficial health effect for antioxidant-rich foods, such as reducing the risk of non-communicable diseases and premature ageing [34].

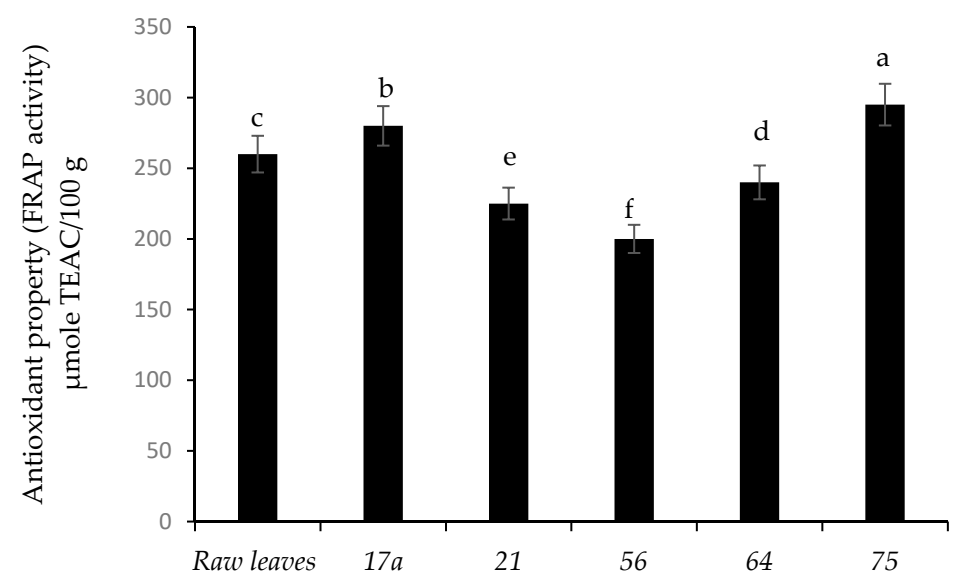

Figure 5. Influence of lactic acid fermentation of Lactobacillus strains on antioxidant activity (FRAP activity) of African nightshade leaves (Solanum retroflexum).

Each value represents the mean value of five replicate samples. Means followed by the same letter are not significantly different $(p<0.05)$.

\subsection{Proximate Analysis}

Proximate analysis was undertaken in the product showing reduced color difference and the highest antioxidant property in nightshade leaves after fermenting with LAB strains. On that basis, the leaves chosen for proximate analysis underwent fermentation with LAB strain 75; details are in Table 2. Fat and carbohydrates were low in fermented leaves. Lower calorific carbohydrate is associated with the lower calculated energy $136.96 \mathrm{~kJ}$ or $32.73 \mathrm{cal} / 100 \mathrm{~g}$ of leaves. Since the total caloric value is less than $300 \mathrm{cal}$, fermented nightshade leaves are a low-calorie product. The final fermented product was low in protein and fiber but high in Na content. Na intake is set at $2.253 \mathrm{mg}$ per day, according to the USDA dietary guidelines [35], and $0.98 \mathrm{~g}$ fermented nightshade leaves contributed to that portion.

Table 2. Proximate analysis data of the nightshade leaves fermented with L. plantarum strain 75.

\begin{tabular}{cc}
\hline Component & Per Fermented Vegetable (100 g Fresh Weight) \\
\hline Energy $(\mathrm{kJ})$ & 136.96 \\
Moisture $(\mathrm{g})$ & $81.51 \pm 0.22 *$ \\
Fat $(\mathrm{g})$ & $0.23 \pm 0.03$ \\
Protein $(\mathrm{g})$ & $3.86 \pm 0.19$ \\
Carbohydrate $(\mathrm{g})$ & $2.51 \pm 0.05$ \\
Fibre $(\mathrm{g})$ & $2.52 \pm 0.30$ \\
Ash $(\mathrm{g})$ & $9.91 \pm 0.50$ \\
Na (sodium) $(\mathrm{mg})$ & $231.00 \pm 2.81$ \\
\hline
\end{tabular}

* Standard deviation, $n=3$ 


\section{Conclusions}

Different LAB strains used in this study affected the concentrations of phenolic components and the antioxidant activity of nightshade leaves; however, the greater impact depends on the strain used during fermentation. LAB strains isolated from fermented vegetables exhibit numerous functional properties [36-40]. Among those, L. plantarum is the species that has been focused on in most studies. The ability of this bacterium to modulate antioxidant activity and phenolic compound composition appears strain-dependent, but also dependent on the matrix investigated. L. plantarum strain 75 is a potential starter culture for the improvement of phenolic composition in nightshade leaves compared to the other strains, and it enhanced the use of nightshade leaves as a functional ingredient or food. Since increased concentrations of phenolic compounds can affect the astringency or bitterness of nightshade leaves, sensory evaluation is necessary in the future. Phenolic compounds are associated with health benefits, such as anti-diabetic activity, and performing biological activities after fermenting the nightshade leaves with L. plantarum 75 shows their beneficial effects.

Supplementary Materials: The following are available online at http://www.mdpi.com/2076-2607/8/9/1324/s1, Figure S1: Chromatogram showing the changes in gallic acid concentration and pyragallol during fermentation by Weissella cibaria (strain 21) and Lactobacillus plantarum (strain 75), Table S1: Pearson's correlation coefficients of phenolic profiles and antioxidant (FRAP) activities.

Author Contributions: A.D.: Performed the experiment; responsible for the data collection; formal analysis; writing the first draft. V.M.: Data validation; responsible for analysis of phenolic compounds; statistical analysis; writing the first draft of the manuscript. C.G.: Co-supervisor of the first author; participated in review and editing. F.R.: Conceptualized the research idea; main supervisor of the first author; microbiological analysis review and editing. D.S.: Grant holder; hosting the first author; project administration; resources; revised the final draft; the discussion. All authors have read and agreed to the published version of the manuscript.

Funding: A.D. mobility was funded by Region Reunion and Université de La Réunion.

Acknowledgments: The financial support from the National Research Foundation, South Africa and (Grant number 98352) for Phytochemical Food Network to Improve Nutritional Quality for Consumers is greatly appreciated.

Conflicts of Interest: Authors do not have any conflict of interest to declare.

\section{Abbreviations}

$\begin{array}{ll}\text { ANOVA } & \text { Analysis of variance } \\ \text { DAD } & \text { Diode array detector } \\ \text { FRAP } & \text { Ferric Reducing Antioxidant Power } \\ \text { GRAS } & \text { Generally regarded as safe } \\ \text { HPLC } & \text { High-performance liquid chromatography } \\ \text { LAB } & \text { Lactic acid bacterium } \\ \text { LSD } & \text { Least significant difference } \\ \text { TEAC } & \text { Trolox equivalent antioxidant capacity } \\ \text { TPC } & \text { Total polyphenolic content } \\ \text { TSS } & \text { Total soluble solids } \\ \text { MRS } & \text { Man Rogosa Sharpe } \\ \text { USDA } & \text { United States Department of Agriculture }\end{array}$

\section{References}

1. Managa, M.; Sultanbawa, Y.; Sivakumar, D. Effects of different drying methods on untargeted phenolic metabolites, and antioxidant activity in Chinese cabbage (Brassica rapa L. subsp. chinensis) and nightshade (Solanum retroflexum Dun.). Molecules 2020, 25, 1326. [CrossRef] [PubMed]

2. Oguntoyinbo, F.A.; Fusco, V.; Cho, G.-S.; Kabisch, J.; Neve, H.; Bockelmann, W.; Huch, M.; Frommherz, L.; Trierweiler, B.; Becker, B.; et al. Produce from Africa's gardens: Potential for leafy vegetable and fruit fermentations. Front. Microbiol. 2016, 7, 981. [CrossRef] [PubMed]

3. Fessard, A.; Remize, F. Genetic and technological characterization of lactic acid bacteria isolated from tropically grown fruits and vegetables. Int. J. Food Microbiol. 2019, 301, 61-72. [CrossRef] [PubMed] 
4. Gao, H.; Wen, J.; Hu, J.; Nie, Q.X.; Chen, H.H.; Nie, S.P.; Xiong, T.; Xie, M.Y. Momordica charantia juice with Lactobacillus plantarum fermentation: Chemical composition, antioxidant properties and aroma profile. Food Biosci. 2019, 29, 62-67. [CrossRef]

5. Fujita, A.; Sarkar, D.; Genovese, M.L.; Shetty, K. Improving anti-hyperglycemic and anti-hypertensive bioactive properties of camu-camu (Myriciaria dubia Mc. Vaugh) using lactic acid bacterial fermentation. Process Biochem. 2017, 59, 133-140. [CrossRef]

6. Wafula, E.N.; Franz, C.M.A.P.; Rohn, S.; Huch, M.; Mathara, J.M.; Trierweiler, B.; Becker, B. Fermentation of African Leafy Vegetables to Lower Postharvest Losses, Maintain Quality and Increase Product Safety. Afr. J. Hortic. Sci. 2016, 9, 13.

7. Karovičová, J.; Kohajdová, Z. Lactic acid fermented vegetable juices. Hortic. Sci. 2011, 30, 152-158. [CrossRef]

8. Quattrini, M.; Korcari, D.; Ricci, G.; Fortina, M.G. A polyphasic approach to characterize Weissella cibaria and Weissella confusa strains. J. Appl. Microbiol. 2020, 128, 500-512. [CrossRef]

9. Srionnual, S.; Yanagida, F.; Lin, L.H.; Hsiao, K.N.; Chen, Y.S. Weissellicin 110, a newly discovered bacteriocin from Weissella cibaria 110, isolated from plaa-som, a fermented fish product from Thailand. Appl. Environ. Microbiol. 2007, 73, 2247-2250. [CrossRef]

10. Association of Official Analytical Chemists (AOAC). Official Methods of Analysis of AOAC International, 17th ed.; AOAC International: Gaithersburg, MD, USA, 2000.

11. Mpai, S.; du Preez, R.; Sultanbawa, Y.; Sivakumar, D. Phytochemicals and nutritional composition in accessions of Kei-apple (Dovyalis caffra): Southern African indigenous fruit. Food Chem. 2018, 253, 37-45. [CrossRef]

12. Zeb, A. A reversed phase HPLC-DAD method for the determination of phenolic compounds in plant leaves. Anal. Methods 2015, 18, 7753-7757. [CrossRef]

13. Ruiz Rodríguez, L.G.; Mohamed, F.; Bleckwedel, J.; Medina, R.B.; De Vuyst, L.; Hebert, E.M.; Mozzi, F. Diversity and functional properties of lactic acid bacteria isolated from wild fruits and flowers present in Northern Argentina. Front. Microbiol. 2019, 10, 1019. [CrossRef] [PubMed]

14. Fessard, A.; Kapoor, A.; Patche, J.; Assemat, S.; Hoarau, M.; Bourdon, E.; Bahorun, T.; Remize, F. Lactic fermentation as an efficient tool to enhance the antioxidant activity of tropical fruit juices and teas. Microorganisms 2017, 5, 23. [CrossRef] [PubMed]

15. Lübeck, M.; Stephensen Lübeck, P. Application of lactic acid bacteria in green biorefineries. FEMS Microbiol. Lett. 2019, 366, 160-167. [CrossRef] [PubMed]

16. Xiong, T.; Guan, Q.; Song, S.; Hao, M.; Xie, M. Dynamic change of lactic acid bacteria flora during Chinese sauerkraut fermentation. Food Control 2012, 26, 178-181. [CrossRef]

17. Chen, L.; Opara, U.L. Texture measurement approaches in fresh and processed foods-A review. Food Res. Int. 2013, 51, 823-835. [CrossRef]

18. Kaprasob, R.; Kerdchoechuen, O.; Laohakunjit, N.; Sarkar, D.; Shetty, K. Fermentation-based biotransformation of bioactive phenolics and volatile compounds from cashew apple juice by select lactic acid bacteria. Process Biochem. 2017, 59, 141-149. [CrossRef]

19. Zubaidah, E.; Ifadah, R.A.; Afgani, C.A. Changes in chemical characteristics of kombucha from various cultivars of snake fruit during fermentation. In International Conference on Green Agro-Industry and Bioeconomy, IOP Conference Series: Earth and Environmental Science; IOP Publishing: Bristol, UK, 2019; Volume 230, p. 012098.

20. Abou-Zaid, F.O.F.; Ibraheem, A.A. Using of some different acids in de-bittering OF green olives. J. Food. Dairy Sci. 2015, 6, 393-404. [CrossRef]

21. Ramírez, E.; Gandul-Rojas, B.; Romero, C.; Brenes, M.; Gallardo-Guerrero, L. Composition of pigments and color changes in green table olives related to processing type. Food Chem. 2015, 166, 115-124. [CrossRef]

22. Filannino, P.; Cavoski, I.; Thlien, N.; Vincentini, O.; DeAngelis, M.; Silano, M.; Gobbetti, M.; Di Cagno, R. Lactic acid fermentation of cactus cladodes (Opuntia ficus-indica L.) generates flavonoid derivatives with antioxidant and anti-inflammatory properties. PLOS ONE 2016, 11, e0152575.

23. Jagannath, A.; Raju, P.S.; Bawa, A.S. Controlled lactic fermentative stabilization of ascorbic acid in amaranthus paste. LWT-Food Sci. Technol. 2012, 48, 297-301. [CrossRef]

24. Tayo, B.A.; Akpeji, S. Probiotic viability. Physicochemical and sensory properties of probiotic pineapple juice. Fermentation 2016, 2, 20. 
25. Apramita, D.; Appaiaha, K.A. Diverse physiological and metabolic adaptations by Lactobacillus plantarum and Oenococcus oeni in response to the phenolic stress during wine fermentation. Food Chem. 2018, 268, 101-109.

26. Okcu, G.; Ayhan, K.; Altuntas, E.G.; Vural, N.; Poyrazoglu, E.S. Determination of phenolic acid decarboxylase produced by lactic acid bacteria isolated from shalgam (şalgam) juice using green analytical chemistry method. LWT-Food Sci Technol. 2016, 66, 615-621. [CrossRef]

27. Rodríguez, H.; Landete, J.M.; de las Rivas, B.; Muñoz, R. Metabolism of food phenolic acids by Lactobacillus plantarum CECT 748 ${ }^{\mathrm{T}}$. Food Chem. 2008, 107, 1393-1398. [CrossRef]

28. Silva, I.; Campos, F.M.; Hogg, T.; Couto, J.A. Wine phenolic compounds influence the production of volatile phenols by wine-related lactic acid bacteria. J. Appl. Microbiol. 2011, 111, 360-370. [CrossRef]

29. Jiménez-López, J.; Ruiz-Medina, A.; Ortega-Barrales, P.; Llorent-Martínez, E.J. Phytochemical profile and antioxidant activity of caper berries (Capparis spinosa L.): Evaluation of the influence of the fermentation process. Food Chem. 2018, 250, 54-59. [CrossRef]

30. Gan, R.U.; Shah, N.P.; Wang, M.F.; Lui, W.Y.; Corke, H. Fermentation alters antioxidant capacity and polyphenol distribution in selected edible legumes. Int. J. Food Sci. Technol. 2016, 51, 875-884. [CrossRef]

31. Landete, J.M.; Curiel, J.A.; Rodríguez, H.; de las Rivas, B.; Muñoz, R. Aryl glycosidases from Lactobacillus plantarum increase antioxidant activity of phenolic compounds. J. Funct. Foods 2014, 7, 322-329. [CrossRef]

32. Zhou, Y.; Wang, R.; Zhang, Y.; Yang, Y.; Sun, X.H.; Zhang, Q.; Yang, N. Biotransformation of phenolics and metabolites and the change in antioxidant activity in kiwifruit induced by Lactobacillus plantarum fermentation. J. Sci. Food Agric. 2020, 100, 3283-3290. [CrossRef]

33. Kaltsa, A.; Papaliaga, D.; Papaioannou, E.; Kotzekidou, P. Characteristics of oleuropeinolytic strains of Lactobacillus plantarum group and influence on phenolic compounds in table olives elaborated under reduced salt conditions. Food Microbiol. 2015, 48, 58-62. [CrossRef] [PubMed]

34. Grosso, G. Dietary Antioxidants and Prevention of Non-Communicable Diseases. Antioxidants 2018, 7, 94. [CrossRef] [PubMed]

35. USDA Dietary Guidelines. Dietary Guidelines for Americans 2015-2020. Available online: https://www. dietaryguidelines.gov/sites/default/files/2019-05/2015-2020_Dietary_Guidelines.pdf (accessed on 13 April 2020).

36. Tamang, J.P.; Tamang, B.; Schillinger, U.; Guigas, C.; Holzapfel, W.H. Functional properties of lactic acid bacteria isolated from ethnic fermented vegetables of the Himalayas. Int. J. Food Microbiol. 2009, 135, $28-33$. [CrossRef] [PubMed]

37. Alan, Y.; Topalcengiz, Z.; Dı̆̆rak, M. Biogenic amine and fermentation metabolite production assessments of Lactobacillus plantarum isolates for naturally fermented pickles. LWT-Food Sci. Technol. 2018, 98, 322-328. [CrossRef]

38. Xu, X.; Luo, D.; Bao, Y.; Liao, X.; Wu, J. Characterization of diversity and probiotic efficiency of the autochthonous lactic acid bacteria in the fermentation of selected raw fruit and vegetable juices. Front. Microbiol. 2018, 9, 2539. [CrossRef] [PubMed]

39. Septembre-Malaterre, A.; Remize, F.; Poucheret, P. Fruits and vegetables, as a source of nutritional compounds and phytochemicals: Changes in bioactive compounds during lactic fermentation. Food Res. Int. 2018, 104, 86-99. [CrossRef]

40. Szutowska, J. Functional properties of lactic acid bacteria in fermented fruit and vegetable juices: A systematic literature review. Eur. Food Res. Technol. 2020, 246, 357-372. [CrossRef]

C 2020 by the authors. Licensee MDPI, Basel, Switzerland. This article is an open access article distributed under the terms and conditions of the Creative Commons Attribution (CC BY) license (http://creativecommons.org/licenses/by/4.0/). 